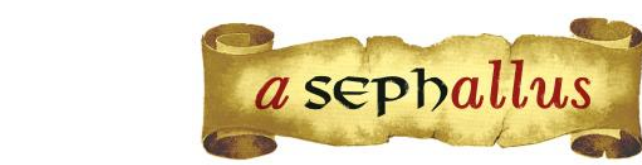

Revista aSEPHallus de Orientação Lacaniana

Núcleo Sephora de Pesquisa sobre o Moderno e o Contemporâneo

ISSN $1809-709 \mathrm{X}$

\title{
Entre missionários e mercenários: um estudo sobre o caráter manifesto no campo profissional contemporâneo da medicina
}

\section{Lúcia Helena Carvalho dos Santos Cunha}

Psicanalista

Doutora em teoria psicanalítica / UFRJ (Rio de Janeiro, Brasil)

Mestre em ciências, área de saúde mental/ENSP/FIOCRUZ (Rio de Janeiro, Brasil)

Professora Adjunta da UNIFESO, no Hospital das Clínicas de Teresópolis (Rio de Janeiro,

Brasil)

Membro do ISEPOL - Instituto Sephora de ensino e pesquisa de orientação lacaniana (Rio de Janeiro, Brasil)

E-mail: luciahelenacunha@gmail.com

Resumo: Novas formas de subjetivação, produzidas pelo discurso dominante na contemporaneidade, se mostram presentes entre profissionais que atuam na medicina. Tradicionalmente imbuídos do espírito missionário, os médicos atestam o surgimento entre eles de um novo perfil, que nomearemos como mercenário. Em tempos de afrouxamento do supereu, sob o império do narcisismo, o direito ao gozo se manifesta no meio profissional através desse novo perfil. Vamos, por isso, examinar através da teoria psicanalítica a formação do caráter, enquanto construção derivada da libido, considerando que essa formação psíquica determina a maneira como o sujeito lida com seu gozo e tem implicações para sua conduta ética e moral no trabalho.

Palavras-chave: psicanálise; gozo; caráter; profissão médica; missionários; mercenários.

\section{Entre missionaires et mercenaires: une étude du charactère manifeste dans le domaine professionel de la médecine}

Des nouvelles formes de subjectivité, produites par le discours dominant dans l'époque contemporaine, surgissent parmi les professionnels de la médecine. Traditionnellement impregnés de l'esprit missionaire, les médecins témoignent l'émergence parmi eux d'un nouveau profil que nous allons appeller mercenaire. Dans les périodes creuses du surmoi, pendant l'empire du narcissisme, le droit à la jouissance se manifeste dans le milieu professionnel grâce à ce nouveau profil. Examinons donc, atravers de la théorie psychanalytique, la formation du caractere en tant que derivé de la libido, sachant que cette formation psychique determine la façon dont le sujet fait face à la joie et a des conséquences sur sa conduite morale et étique au travail.

Mots-clés: psychanalyse; jouissance; caractere; profession médicale; missionaires; mercenaires.

\section{Among missionaries and mercenaries: a study on the manifest character in the professional field of medicine}

New forms of subjectivity produced by the dominant discourse in contemporary times appear among medicine professionals. Doctors- traditionally imbued with the missionary spirit - testify to the emergence among them of a new profile, which we will name as mercenary. In times of slackness of the superego, when narcissism reigns, the right to enjoyment manifests itself in the professional environment through this new profile. Therefore, we intend to examine using psychoanalytic theory the formation of character as a construction derived from libido considering that this psychic formation determines how the individual deals with joy and that it also has implications for the moral and ethical conduct at work.

Key-words: psychoanalysis; enjoyment; character; medical profession; missionaries; mercenaries. 


\title{
Entre missionários e mercenários: um estudo sobre o caráter manifesto no campo profissional contemporâneo da medicina
}

\author{
Lúcia Helena Carvalho dos Santos Cunha
}

\section{Introdução}

O predomínio de uma ideologia individualista associada ao capitalismo neoliberal vem arrastando consigo a produção de novas subjetividades, submetidas ao consumismo e às compulsividades, entre outras manifestações do direito ao gozo, como as que estão se tornando visíveis no mercado de trabalho em saúde. Nesse novo tempo, quando se anuncia que tudo é possível, a relação entre oferta e procura de objetos de satisfação se vê alterada pelo empuxo desenfreado ao consumo; o mercado produz o que se deve desejar. A contemporaneidade não revela mais uma subjetividade regulada pelo princípio do prazer, mas sim sujeitos que buscam o gozo narcísico determinado pelos imperativos ditados pelo mercado. Entre profissionais da medicina, tradicionalmente altruístas e missionários, localizamos, em nossa pesquisa, o surgimento de um novo perfil: nomeamos esses sujeitos como mercenários, voltados exclusivamente para o comércio profissional, como um grupo em expansão nos dias de hoje (Cunha, 2015).

Surge nesta cultura do narcisismo uma completa rejeição ao inconsciente, com a redução de todo saber ao diploma universitário (Coelho dos Santos, 2008): o saber se transforma também numa mercadoria que se compra e se vende desacompanhado da autoridade daquele que o transmite. Estando o objeto a no comando da civilização (Miller, 2004), a busca perversa do gozo a qualquer preço instala o poder acéfalo da pulsão na (des)ordem do dia: tempo do vale-tudo, quando se acredita que tudo seja possível. Este excesso de gozo se faz notar pelo aparecimento de novos sintomas sociais, entre os quais localizamos o burnout, frequentemente diagnosticado neste grupo, e tomado como como doença profissional entre profissionais de saúde (Coelho dos Santos \& Cunha, 2013).

Em função dessa leitura, passaremos a tomar este sintoma como resultante das modificações introduzidas pelo discurso dominante no campo de trabalho dos médicos contemporâneos, supondo que novas formas de subjetivação estão se tornando frequentes neste campo de trabalho. Vamos, por isso, passar ao exame da formação do caráter, considerando que essa formação psíquica determina a maneira como o sujeito lida com seu direito ao gozo, e determina a maneira como os profissionais se comportam do ponto de vista ético e moral. Levando em consideração a diferença entre missionários e mercenários, procuraremos examinar, através do estudo psicanalítico do caráter, como essa formação subjetiva é afetada pelo discurso vigente na contemporaneidade.

\section{Um estudo sobre o conceito psicanalítico de caráter}

Freud abordou as manifestações pulsionais que se fazem conhecer através do caráter. Esse foi um tema que ele trabalhou em alguns textos, entre os quais os mais importantes para nosso 
raciocínio são: "Caráter e erotismo anal" (Freud, 1908/1980); e "Alguns tipos de caráter encontrados no trabalho psicanalítico" (Freud, 1916/2010). Em 1908, Freud comentou três características de comportamento que the pareciam estar interligados, relacionadas às pessoas ordeiras, parcimoniosas e obstinadas. Todas adviriam do desaparecimento do erotismo anal, presente na primeira infância a partir do amadurecimento funcional do esfíncter anal. A tarefa de educação dos esfíncteres, importante conquista civilizatória no processo de socialização, exige disciplina no controle sobre o funcionamento corpo; mas implica em renúncia à liberdade de que a criança usufrui, até os dois anos de idade. Liberdade para gozar, a qualquer hora, com os estímulos eróticos originados pelo erotismo anal.

Já em 1905 Freud havia publicado, em seus "Três ensaios sobre a teoria da sexualidade" (Freud, 1905/1980) sua teoria sobre o apoio que a pulsão sexual encontra nas zonas erógenas corporais como a boca, o ânus, a pele, os órgãos do sentido e os órgãos sexuais: a excitação do órgão é o que confere caráter sexual à pulsão (Freud, 1905/1980, p. 186). Os sentimentos de asco e vergonha e as construções sociais da moral e da autoridade foram indicadas como resultantes das exigências parentais feitas à criança no sentido de alcançar o controle e a educação corporal necessárias à sua educação social. A partir da íntima associação entre as exigências sociais e sentimentos adquiridos a partir da formação moral Freud estudou as relações entre o erotismo anal e a formação do caráter adquirido pela educação parental administrada à criança.

Efeito da renúncia às exigências pulsionais de satisfação (por esta via direta), esta educação se dá na negociação entre a demanda da mãe e a entrega, pela criança, do produto corporal que, doravante, será associado à sujeira e a tudo que deve ser eliminado. Mas que destino foi dado à pressão pulsional em suas exigências de satisfação que eram atendidas através do erotismo anal? Freud deduz, pela observação clínica, que ela não desaparece; ela é desviada para outras finalidades, sendo empregada em sua maior parte na vida social, no trabalho, nas amizades, sublimada nos relacionamentos. $\mathrm{O}$ erotismo anal sublimado é uma fonte importante de energia psíquica para o trabalho, um destino pulsional que determina o comportamento profissional. Mas, além dessa descoberta, Freud faz outra dedução muito importante, que nos interessa vivamente:

Uma subvariedade da sublimação talvez seja a supressão por formação reativa, que, como descobrimos, começa no período de latência da criança e, nos casos mais favoráveis, prossegue por toda a vida. Aquilo a que chamamos "caráter" de um homem constrói-se, numa boa medida, a partir do material das excitações sexuais, e se compõe de pulsões fixadas desde a infância, de outras obtidas por sublimação, e de construções destinadas ao refreamento eficaz de moções perversas reconhecidas como inutilizáveis. (Freud, 1905/1980, p. 246, grifos meus) 
A formação do caráter, para Freud provém, portanto, desta transformação que sofre o destino pulsional, na medida em que a satisfação buscada pode se realizar por outros meios. Assim, o sujeito aceita se submeter às exigências sociais sem precisar, de fato, abrir mão de sua realização erótica, satisfeita por outras vias. Seja através da sublimação, seja através da formação reativa, que literalmente faz do vício uma virtude: "Por conseguinte, a disposição sexual universalmente perversa da infância pode ser considerada como a fonte de uma série de nossas virtudes na medida em que, através da formação reativa, impulsiona a criação delas" (Freud, 1905/1980, p. 182).

Prosseguindo em sua investigação teórica sobre as neuroses, Freud publicou o texto "A predisposição à neurose obsessiva: contribuição ao problema da escolha da neurose" (Freud, 1913/2010) quando observou, em relação ao desenvolvimento do caráter, que nele encontramos as mesmas forças pulsionais que operam nas neuroses. O que, então, diferencia o caráter do comportamento neurótico? Freud diz que o fracasso do recalcamento e subsequente retorno do recalcado, peculiares ao mecanismo da neurose, estão ausentes na formação do caráter. Em função disso, as formações reativas e sublimações se manifestam como outros destinos pulsionais possíveis, além do recalque. Entretanto, comenta que esses destinos são menos observáveis para o analista, que não consegue interpretá-los facilmente. Propomos considerar que eles aparecem mais claramente nas escolhas profissionais e nos tipos de conduta assumidos nas relações de trabalho.

Freud deduziu que o caráter se manifesta a partir da adesão da libido ao erotismo anal, especialmente oriundo do estágio anal-sádico. O caráter seria a forma visível da manifestação, transformada, desse erotismo. E apresentou, como prova de seu raciocínio, um divertido exemplo: o de mulheres que encerraram sua vida sexual e se tornaram briguentas, despóticas, sovinas e irritantes! A regressão ao referido estágio é a responsável pela mudança de caráter amplamente observado nesses casos. Estas mulheres protagonizariam a transformação de caráter das moças anteriormente encantadoras: esposa - amante e mãe terna se transformam em um verdadeiro dragão! Freud produziu tais observações apoiado nas sátiras produzidas pelos autores de comédia de sua época. Voltando ao tema deste artigo, destacamos que "O caráter é muito mais um modo de ser e de viver" (Coelho dos Santos \& Azeredo, 2005, p. 87). Diferente do sintoma neurótico, que leva o sujeito a manifestar um estado de queixas ou a procurar ajuda num tratamento psicanalítico em função do seu estado de sofrimento.

O mecanismo da formação reativa, entretanto, pode ser observado tanto na neurose obsessiva quanto na formação do caráter e, por isso, devemos considerar cuidadosamente em que condições ocorre a formação reativa. Freud as diferenciou a partir do que ocorre nesta última: em seus termos, "com facilidade", operando uma regressão ao estágio anal, após o recalcamento bemsucedido (Freud, 1913/2010, p. 334). Já no primeiro caso, o das neuroses obsessivas, havendo um fracasso do recalque, a defesa se faz de maneira conflitada, uma vez que se faz necessário, desta vez, um esforço em não admitir a regressão, lançando mão então das formações reativas, agindo contra a regressão ao erotismo sádico anal. Os sintomas obsessivos são apresentados como o fruto 
da conciliação entre os lados opostos, numa cisão das atividades mentais, que torna alguns pensamentos admissíveis à consciência enquanto outros permanecem inconscientes (Freud, 1913/2010, p. 334).

A diferença que é ressaltada entre o sintoma e o caráter interessa ao campo dessa pesquisa, uma vez que o sintoma profissional mais frequente entre médicos, se acompanharmos Freud, surgiria de algum conflito entre as pulsões sádicas e sua forma de satisfazê-las na vida profissional. Neste ponto, uma neurose se estabelece e o conflito se torna evidente. Já a formação reativa que forma o caráter é bem-sucedida na tarefa de transformar as pulsões hostis e agressivas. Eis uma diferença que pode ser verificada, em relação ao posicionamento dos médicos diante de sua vida pulsional e, para prosseguirmos no estudo da oposição entre missionários e mercenários, vamos precisar nos ater ao sucesso ou ao fracasso da defesa que o sujeito estrutura diante do gozo pulsional quando este é interditado socialmente.

Coelho dos Santos e Azeredo, acima citados, lembram que Freud moldou sua teoria do caráter a partir da sua formulação sobre o superego: este se consolida, com maior ou menor consistência, quando do término do complexo de Édipo, através da internalização da lei paterna. Esse é o aspecto que diferencia a interpretação dos achados clínicos. Enquanto as meninas não encerrariam definitivamente esse complexo, alcançando menor consistência na formação do supereu e, consequentemente, do caráter, os meninos o fariam de forma radical - a não ser que falhem nessa tarefa, quando sobrevém o quadro da neurose. O caráter depende, portanto, da formação bemsucedida do supereu e "quanto mais afastado se está dele, menos caráter se tem" (Coelho dos Santos \& Azeredo, 2005, p. 86). Por outro lado, os autores observam que os tempos atuais trouxeram uma forte modificação nos princípios morais que organizavam a sociedade moderna. $\mathrm{Na}$ modernidade esta organização social estava baseada na internalização da lei, na identificação à figura de autoridade comandada pela força que antigamente caracterizava a figura paterna. A lei é a interdição do gozo pulsional, contrário aos interesses da coletividade. A censura moral exercida pelo supereu obriga o sujeito a renunciar ao gozo.

Mas, na contemporaneidade, houve um verdadeiro desmoronamento do lugar social que sustentava o pátrio poder (Coelho dos Santos \& Lopes, 2013), o que vem provocando efeitos, inclusive no aparecimento de novos sintomas. Entre estes, a drogadição, a obesidade mórbida e todo tipo de compulsões - inclusive entre os workaholics - são encontrados com grande frequência nos dias de hoje. Os efeitos subjetivos dessa mudança estariam se manifestando também na formação do caráter de sujeitos mais jovens, reduzindo a censura oriunda do supereu. E, assim, introduzindo uma nova ética na condução dos comportamentos sociais, conforme apuramos numa pesquisa realizada com médicos que atuam em hospitais: eles se queixam do comportamento de jovens profissionais, que não mais atuam como missionários, não mais consideram a medicina um sacerdócio. Não renunciam ao seu fim de semana, evitando plantões nestes dias; não aceitam fazer 
os sacrifícios pela carreira que seus antecessores fizeram quando começaram sua vida profissional (Cunha, 2012; 2015).

Na modernidade, a incorporação da função paterna produzia, na maior parte dos sujeitos, o recalque das pulsões, numa ética de renúncia a prazeres sustentada pela sociedade. Freud indicou a neurose moderna como efeito da moral civilizada que exigia o recalque pulsional, interditando o gozo. Já o modo de subjetivação contemporâneo estaria produzindo menor renúncia às satisfações imediatas, prescindindo do mecanismo do recalque. A satisfação da pulsão podendo ser alcançada, nos dias de hoje, por outros caminhos que não os do sintoma neurótico. Acreditamos que, em função disso, um novo tipo de caráter está se tornando visível no meio profissional médico por meio de um modo inédito de gozo denunciado pelos médicos mais antigos na profissão. Nós o abordaremos como produzindo um novo perfil do profissional, evidenciado na pesquisa de campo pelas queixas que são dirigidas, de maneira genérica, a profissionais mais jovens que se recusam a cumprir 0 mesmo percurso trilhado pelos que os precederam.

Este perfil, que por um lado não é inteiramente novo - pois sujeitos avarentos e mercenários sempre existiram -, por outro recebe $o$ incremento de uma nova mentalidade social que autoriza 0 gozo consumista, promovendo uma modificação no ritmo e na característica do trabalho do médico - como recolhemos do relato de um estudante de medicina. Este observou sua trajetória pessoal ao longo dos anos de formação universitária: inicialmente motivado a colocar o paciente no foco de seu trabalho, passou agora, ao final de seu curso, a considerar que agora este é apenas "mais um numa fila de segurados". O estudante percebe-se hoje mais interessado em atender no menor tempo o maior número de pacientes, otimizando seus ganhos junto à seguradora de saúde. Fazer muitos atendimentos pelos convênios, dar múltiplos plantões durante a semana e adquirir um bom padrão de vida para desfrutar junto à sua família é seu plano de vida atual, às custas de forte desgaste físico e emocional. A profissão não mais exige dele uma renúncia aos interesses pessoais em prol de alguma missão idealizada.

Apontamos, por seu intermédio, a entrada do direito ao gozo narcísico na prática médica, devido à redução do papel do supereu na formação subjetiva contemporânea. Esse direito estaria alterando a relação ética que tradicionalmente caracterizava a relação profissional no campo da saúde. Alguns exemplos de práticas profissionais nesta área indicam a multiplicação da atuação de sujeitos cujo caráter mercenário se anuncia claramente: os empresários de saúde aparecem como atravessadores da relação entre o médico e seu paciente, auferindo um grande lucro financeiro, a partir do atendimento médico. A imprensa noticia situações antes desconhecidas ou inexistentes, como o agenciamento de médicos na colocação de próteses desnecessárias; denuncia a prática (muitas vezes corrente) entre alguns profissionais que cobram, de pacientes do SUS, um pagamento para realizar imediatamente cirurgias que deveriam ser gratuitas. O caráter retentivo anal parece ser estimulado abertamente na formação subjetiva contemporânea. Constatamos que a economia 
capitalista requer sujeitos em condições de gastar desenfreadamente e consumir vorazmente num regime libidinal onde a antiga temperança perdeu o seu valor.

Miller (2006) destaca que, na medida em que o caráter não se oferece à interpretação, não se deixa ler como uma formação do inconsciente. Sob este aspecto, o caráter se mostra próximo a uma experiência do real. A orientação para o real é visada por Lacan ao final de seu ensino, quando ele não mais privilegia a busca do sentido. Por esta razão, o estudo dos traços de caráter pode trazer informações importantes para os psicanalistas, indicando o real em questão. Em Freud, encontramos a busca para a significação do sintoma, que se articulava à experiência de satisfação pulsional no campo do desejo, orientado pelo ideal do eu. Já o último Lacan se ateve ao valor de gozo presente nos sujeitos, indicando um tipo de satisfação que não se dirige ao Outro e que escapa ao campo do sentido. Miller também chama a atenção para o fato de que Freud encontrou no caráter aquilo que não fez o mesmo caminho que o sintoma. O caráter aproxima-se, a seu ver, mais da realização de gozo, indicada por Freud pelo termo alemão Befriedigung, traduzido como satisfação. Miller observa que Freud se serviu de um outro termo, o de Bedeutung para indicar a significação do sintoma e isso o leva a destacar que é a satisfação da Befriedigung que localiza a constituição do caráter como mais próxima do gozo pulsional e do campo do real.

Assim, Miller traz novos argumentos para acentuar a diferenciação freudiana entre sintoma e caráter, embora ambos revelem ser modos de satisfação da pulsão. A definição do caráter, recolhida por Miller do trabalho freudiano, indica "aquilo que, no sujeito, não se satisfaz pelo sintoma, e que se parece com um modo de satisfação da pulsão que não mobiliza o sintoma como uma mensagem do Outro" (Miller, 2006, p. 119). Além disso, Miller considera que, ao longo de sua obra, Freud deslocou gradualmente o acento de suas preocupações com o sintoma para a conduta do sujeito, para as repetições, as defesas e o caráter. Comentando a abordagem do caráter realizada por Otto Fenichel, Miller considera que o que foi chamado por aquele de personalidade diz respeito ao conceito freudiano de caráter (Miller, 2006, p. 151).

Destacamos este aspecto como importante ao enfatizar, mais uma vez, que encontramos na nossa pesquisa de campo uma indicação de que está havendo uma modificação na formação de caráter apresentada entre médicos. Segundo vários depoimentos, muitos médicos hoje em dia apresentam um comportamento profissional bastante diferente do que caracteriza o caráter do médico tradicional. Essa diferença aponta para uma forma de satisfação pulsional comum nos sujeitos contemporâneos, voltados para a concentração de bens materiais. Fenichel, inclusive, associou a tendência a acumular riqueza, presente no erotismo anal, com o capitalismo; aspecto que precisamos ressaltar neste trabalho. A moralidade em jogo no capitalismo tardio introduz claras mudanças frente às formas de regulação dos comportamentos sociais praticados anteriormente, na modernidade.

Queremos destacar também a distância existente entre os sujeitos médicos que produzem os sintomas clássicos da neurose obsessiva (visível na chamada "síndrome do cuidador descuidado"1 
e no fantasma oblativo recorrente no perfil do médico missionário) e aqueles que apresentam, na formação de seu caráter, traços que os caracterizam como sujeitos narcisistas, interessados na realização de suas necessidades individuais, com menor regulação pelo ideal do eu e que estamos relacionando ao perfil mercenário.

Para concluir essa questão das alterações do caráter, lembraremos os diferentes tipos de caráter estudados por Freud em 1916. Considerando o comentário de Miller - de que a descrição freudiana do caráter pode ser tomada como uma posição subjetiva frente ao gozo, por ser uma forma diferenciada de lidar com a exigência pulsional - destacaremos os três tipos de caráter apresentados por Freud no texto intitulado Alguns tipos de caráter encontrados no trabalho psicanalítico (Freud, 1916/2010), a saber: os que se consideram como exceções; os que fracassam pelo êxito; e os que são criminosos devido ao sentimento de culpa.

Coelho dos Santos e Azeredo (2005) observaram, a partir desse texto de Freud, que um tipo excepcional de caráter, o das exceções, vem se destacando nos dias atuais. As modificações sociais, culturais, que vêm se dando em nossos tempos pós-modernos, estimulam os sujeitos a consumirem. Desta maneira, liberando o gozo antes proibido, tais mudanças produzem alterações na posição subjetiva dos sujeitos, que se manifestam através de novas modalidades de caráter. Os dois últimos tipos de caráter descritos no texto de 1916 estariam "caindo em desuso... típicos de uma forma de organização social baseada em uma figura paterna forte, que serve de ideal do eu (...). Em contrapartida, o primeiro tipo, o das exceções, estaria em pleno avanço" (Coelho dos Santos \& Azeredo, 2005, p. 78). Estaríamos, atualmente, diante de uma resistência em renunciar às satisfações fáceis e imediatas, muito maior do que a descrita por Freud em 1916. Exigindo seu direito ao gozo, o sujeito contemporâneo busca ser tratado como uma exceção, desenvolvendo uma posição subjetiva que não o obriga a fazer o esforço de contenção das suas exigências pulsionais, anteriormente produzido pela formação dominante do ideal do eu.

Através de uma alteração na formação do caráter, concluímos que muitos profissionais contemporâneos encontram uma via direta para alcançar a satisfação pulsional. Outros, entretanto, mesmo nos dias atuais, ainda entram em conflito com exigências morais da profissão e, sob ação da censura psíquica, fazem o caminho da neurose, o que os leva à formação de sintomas na configuração clássica promovida pela instância superegóica. Destacamos que o estudo freudiano dos outros dois tipos especiais (os que fracassam diante do êxito e os que cometem crimes por sentimento de culpa) indica que o caráter tanto pode se formar de um modo ou de outro, dependendo da maneira como o sujeito internalizou a lei. Ou seja: a partir da construção subjetiva onde a renúncia ao gozo se institui como uma exigência interna, tal como observamos na formação tradicional que há séculos vem produzindo médicos missionários. Mas, diferentemente destes, encontramos na contemporaneidade o avanço da construção subjetiva lastreada no narcisismo, dos sujeitos que exigem ser tratados como exceções. Verificamos entre estes os sujeitos cujo caráter pode ser moldado pelo direito ao gozo e não pela exigência da renúncia a ele. Donde podemos opor 
o caráter do médico missionário, cuja formação subjetiva se organiza pelo ideal do eu e pela capacidade de renúncia, ao caráter do mercenário, afastado da referência paterna, e voltado para a satisfação narcísica, como uma tendência crescente entre sujeitos contemporâneos.

Entre os missionários e os mercenários, localizaremos os médicos que se decepcionam com a profissão (Cunha, 2015) e que, em crise diante da queda dos ideais humanísticos - que um dia o estimularam a escolher esta profissão -, externam seu conflito subjetivo através do novo sintoma, a síndrome de burnout (esgotamento profissional). Alguns fracassam diante do êxito profissional, evidenciando, na formação de seu caráter, o funcionamento do supereu sádico e cruel que agencia, através da impotência do fantasma, o "acting out"do sintoma. Muitos tornam evidente, através da experiência da despersonalização, a impossibilidade de sustentar seu desejo missionário, em tempos onde não existe mais a mesma sustentação fantasmática de antes, baseada na oblatividade e no altruísmo. É verdade que, apenas no caso a caso de cada experiência, a escuta promovida pela psicanálise poderá reconhecer a posição subjetiva de um profissional; mas, ainda assim, supomos que a consideração à mudança ideológica em andamento poderá auxiliar os psicanalistas no reconhecimento dos aspectos que promovem este sintoma profissional.

\section{Nota:}

${ }^{1}$ Consultar, a respeito, BENEVIDES-PEREIRA, A. M. T. (2002). Burnout: quando o trabalho ameaça o bem-estar do trabalhador. São Paulo: Casa do Psicólogo.

\section{Referências Bibliográficas}

Coelho dos Santos, T. (2005) Prática Lacaniana na Civilização sem Bússola. In Coelho dos Santos, T. (Org.). Efeitos terapêuticos na psicanálise aplicada. Rio de Janeiro: Contracapa, p. 61-92. Coelho dos Santos, T. \& Azeredo, F. A. M. (2005, jul.-dez.). Um tipo excepcional de caráter. Psyché, 9(16), 77-95.

Coelho dos Santos, T. \& Cunha, L. H. C. S. (2013). A saúde dos corpos: entre o ideal missionário e a lógica de mercado). In Freire, A. B. (Org.). O corpo e suas vicissitudes. Rio de Janeiro: 7Letras. Coelho dos Santos, T. \& LOPES, R. G. (2013). Psicanálise, ciência e discurso. Rio de Janeiro: Cia de Freud.

Cunha, L. H. C. S. (2012a). Nem todo dia eles fazem tudo igual: a psicanálise de um sintoma médico. Revista aSEPHallus, 713 . Recuperado de http://www.isepol.com/asephallus/numero 13/artigo 05.html.

Cunha, L. H. C. S. (2012b). Ícaro pós-moderno? Revista aSEPHallus, 713). Recuperado de http://www.isepol.com/asephallus/numero 13/resenha 01.html.

Cunha, L. H. C. S. (2015). A psicanálise aplicada ao sinthoma profissional: uma abordagem do burnout entre médicos. (Tese de doutorado). Programa de Pós-graduação em Teoria Psicanalítica, Instituto de Psicologia da U.F.R.J. 
Freud, S. (1980). Três ensaios sobre a teoria da sexualidade. In J. Salomão (Trad.) Edição standard brasileira das obras psicológicas completas de Sigmund Freud (Vol. 7). Rio de Janeiro: Imago (Trabalho original publicado em 1905).

Freud, S. (1980). Atos obsessivos e práticas religiosas. In J. Salomão (Trad.) Edição standard brasileira das obras psicológicas completas de Sigmund Freud (Vol. 9). Rio de Janeiro: Imago (Trabalho original publicado em 1907).

Freud, S. (1980). Caráter e erotismo anal. In J. Salomão (Trad.) Edição standard brasileira das obras psicológicas completas de Sigmund Freud (Vol. 9). Rio de Janeiro: Imago (Trabalho original publicado em 1908).

Freud, S. (2010). A predisposição à neurose obsessiva. Observações psicanalíticas sobre um caso de paranoia relatado em autobiografia ("O caso Schreber'): artigos sobre técnica e outros textos (1911-1913) (Vol. 10, pp. 324-338). São Paulo: Companhia das Letras (Trabalho original publicado em 1913).

Freud, S. (2010). Alguns tipos de caráter encontrados na prática psicanalítica. Introdução ao narcisismo: ensaios de metapsicologia e outros textos (1914-1916) (Vol. 12, pp. 253-286). São Paulo: Companhia das Letras (Trabalho original publicado em 1916).

Miller, J.-A. (2004/2005, fev.). Uma fantasia. Opção Lacaniana - Revista brasileira internacional de psicanálise, 42. São Paulo: Eólia, p. 7-18.

Miller, J.-A. (2006). La experiencia de lo real en la cura psicoanalitica. Buenos Aires: Paidós.

Citacão/Citation: Cunha, L. H. C. S. (nov. 2015 a abr. 2016). Entre missionários e mercenários: um estudo sobre o caráter manifesto no campo profissional contemporâneo da medicina. Revista aSEPHallus de Orientação Lacaniana, 11(21), 32-41. Disponível em www.isepol.com/asephallus. doi: 10.17852/1809709x.2019v11n21p32-41.

Editor do artigo: Tania Coelho dos Santos.

Recebido/Received: 03/03/2016 / 03/03/2016.

Aceito/Accepted: 07/04/2016 / 04/07/2016.

Copyright: (C) 2013 Associação Núcleo Sephora de Pesquisa sobre o moderno e o contemporâneo. Este é um artigo de livre acesso, que permite uso irrestrito, distribuição e reprodução em qualquer meio, desde que o autor e a fonte sejam citados/This is an open-access article, which permites unrestricted use, distribution, and reproduction in any medium, provided the author and source are credited. 